\title{
FINANÇAS E CONSTRUÇÃO DO ESTADO: FONTES PARA O ESTUDO DA HISTÓRIA TRIBUTÁRIA NO BRASIL DO SÉCULO XIX
}

\author{
Wilma Peres Costa*
}

\section{FISCALIDADE-A ALMA DO ESTADO}

$\mathrm{E}$

mbora seja uma parte limitada do estudo das finanças públicas, a história da fiscalidade constitui um ângulo estratégico para pensar de forma não linear a relação Estado, economia e sociedade, particularmente para aqueles que procuram estudar a construção do Estado como um processo historicamente determinado, que se produz em interação profunda com o corpo social.

A capacidade de extrair, através dos tributos, parte do excedente produzido pela sociedade associa-se, de maneira estreita e reversiva, às outras formas de extração (o recrutamento militar, o ordenamento jurídico) que determinam a consolidação do centro político e o exercício do poder do Estado sobre um território. Assim, o estudo da fiscalidade permite explorar uma das pulsões "universais" que caracterizam o poder do Estado - a pulsão extrativa que é, ao mesmo tempo, condição e resultado do exercício da legitimidade, da soberania, do monopólio da coerção. ${ }^{1}$ A pulsão extrativa gera sempre resistências em diversos níveis -agentes privados, empresas, regiões, poderes locais-, emprestando uma dimensão intrinsecamente conflitiva ao processo extrativo. A discussão da fiscalidade permite, desse modo, olhar para a própria "alma" do Estado, como mostrou Schumpeter. ${ }^{2}$

* Departamento de Política e História Econômica, Instituto de Economia-Unicamp.

1 Um excelente ponto de partida para as "teorias da construção do Estado" pode ser encontrado nos ensaios contidos em Charles Tilly, The formation of national States in Western Europe, Princeton University Press, Princeton, 1975. Sobre as relações reversivas dos processos de extração e coerção ver, na coletânea citada, Samuel Finer, "State and nation-building in Europe: the role of military", pp. 84-164. Ver também Charles Tilly, Coercion, capital and european States (A.D.1990-1992), Oxford, Cambridge, 1990.

2 Joseph Shumpeter, "The crisis of the tax State", International Economic Paper, MacMillan, núm. 4, 1954, Nueva York. 
Talvez a mais fecunda contribuição das teorias da construção do Estado para o conhecimento histórico seja a de propiciar uma compreensão do fenômeno estatal que enfatiza, ao mesmo tempo, o poder do Estado como emanação da sociedade e como expressão da tensão entre o centro político e a ordem econômico-social. A pulsão extrativa de recursos representada pelo fisco permite repensar as relações entre a economia e a política, ao tematizar os limites impostos por uma dada ordem econômica sobre a extração fiscal, como também, reversivamente, nos efeitos dinâmicos do processo extrativo sobre a ordem econômica, reiterando-a e/ou transformando-a. Um exemplo clássico desses efeitos é expresso pelas relações retro-alimentadoras entre o desenvolvimento da economia mercantil e a construção da fiscalidade do Estado Moderno. ${ }^{3}$

Se a pulsão extrativa é uma dimensão "universal" do Estado moderno, a investigação sobre a forma particular pela qual, nas distintas experiências e tempos históricos, se construiu a extração, e os conflitos que se configuraram a partir dela, permite aclarar não apenas os impulsos e limites que uma dada ordem econômico-social imprimem ao processo extrativo como perceber uma chave importante para a compreensão da forma do Estado e da representação política. São, nesse sentido, inspiradoras, as sugestões vindas dos estudos comparados, como as do artigo de Rudolph Braun. ${ }^{4} \mathrm{Nele}$, as trajetórias da Inglaterra e da Prússia são comparadas a partir das relações entre a pulsão fiscal do Estado e as resistências dos grandes proprietários territoriais, como elemento explicativo das diferenças quase polares entre as formas políticas desenvolvidas por aqueles países (parlamentarismo precoce $\mathrm{x}$ absolutismo tardio).

Vistas dessa maneira, enquanto expressão da tensão entre o Estado e as forças sociais, as receitas fiscais ganham um interesse que vai muito além de seu montante e de sua oscilação ao longo de um período de tempo, em direção à questão mais profunda de sua proveniência. $O$ poder do Estado não se avalia apenas pelo quantum que ele é capaz de extrair da ordem econômico-social mas sobretudo da sua capacidade de se impor sobre a esfera do poder privado e sobre os agentes econômicos que o controlam. A construção da fiscalidade, nas opções histórias que lhe dão sentido é reveladora da possibilidade da construção do caráter público do Estado e, porque não dizer, de sua modernidade.

Desse ponto de vista é que o estudo do fisco se torna também estratégico para o estudo da transformação do Estado, em particular no que se refere à questão da representação política. $\mathrm{Na}$ experiência clássica, a crise fiscal foi a dimensão

${ }^{3}$ Sobre a questão fiscal no processo de formação do Estado ver, em o ensaio de Gabriel Ardant, "Financial policy and economic infraestructure of modern States and nations" in Charles Tilly (coord.), The formation, op. cit., pp. 164-243 e sobretudo, Gabriel Ardant, Histoire de l'impôt, Fayard, París, 1971, 2 vols.

${ }^{4}$ Rudolph Braun, "Taxation, sociopolitical structure, and the State-building: Great Britian and Brandemburg Prussia" in Charles Tilly (coord.), The formation, op. cit. 
que condensou os conflitos políticos que marcaram as revoluções burguesas. A ampliação da representação e do controle da sociedade sobre os recursos do Estado tem sido, desde então, uma dimensão crucial da cidadania, embora signifique também uma ampliação da capilaridade e da capacidade extrativa do Estado. A discussão associa-se, do ponto de vista histórico, ao estudo do Estado absolutista europeu e sua forma particular de interação com a ordem econômico social: a desagregação do feudalismo, o conflito de classes e estamentos (burguesia $\mathrm{x}$ nobreza, cidades, ordens, corporações, universidades) e a expansão da economia mercantil que fizeram do campesinato e das cidades a principal fonte da extração fiscal do Estado em construção. A especificidade histórica do processo de construção do Estado europeu em algumas de suas experiências -aquelas onde se encontrava mais desenvolvida a economia mercantil, o campesinato independente e autonomia das cidades- deu uma dimensão duplamente "progressista" ao processo de construção do Estado. No plano econômico fez dele uma alavanca de desintegração do feudalismo e de desenvolvimento capitalista. No plano político, ao incidir sobre a cultura fiscal do feudalismo e sobre as autonomias que caracterizavam o Antigo Regime, propicia a sinergia que irá problematizar cidadania e direitos, taxação e representação.

Recentemente, a crise do socialismo real trouxe uma retomada da discussão teórica e histórica sobre a construção do Estado. Uma parte desse debate levou ao resgate do papel do liberalismo europeu no século XIX enquanto alavanca da reforma do Estado, servindo ao aprofundamento da capilaridade do poder público, ao aumento de sua capacidade extrativa, á legitimação dos exércitos nacionais e da racionalização do aparelho de Estado (divisão de poderes, profissionalização dos funcionários, etc.). ${ }^{5}$

A extração fiscal inerente ao processo de construção estatal estabelece uma dinâmica com a vida econômica e com as forças sociais. Seu resultado não é dado, mas depende de interações históricas que colocam interessantes vias de pesquisa. É importante observar que, centradas no entendimento do Estado absolutista europeu, as teorias da construção do Estado contempladas na coletânea organizada por Tilly, não contemplam a questão do colonialismo europeu entre os séculos XV e XVIII como dimensão relevante do fenômeno estatal. Essa posição contrasta com o tratamento clássico dado por Heckscher ${ }^{6}$ para a ação reversiva entre mercantilismo, colonialismo e construção dos Estados europeus, que teve, na historiografia brasileira um importante desenvolvimento no trabalho clássico de Novais. ${ }^{7}$ Em seu trabalho mais recente,

\footnotetext{
5 Michael Mann, "O poder autônomo do Estado: suas origens, mecanismos e resultados" in John Hall (coord.), Os Estados na história, Imago, Rio de Janeiro, 1992, pp. 163-204.

6 Eli Heckscher, La época mercantilista, Fondo de Cultura Económica, México, 1983, especialmente pp. 17-109.

${ }^{7}$ Fernando Novais, Portugal e o Brasil na crise do Antigo Sistema Colonial, Hucitec, São Paulo, 1975.
} 
Tilly $^{8}$ aponta para uma relação "perversa" entre o colonialismo e os efeitos dinâmicos da construção estatal ao ressaltar o relativo "atraso" do desenvolvimento do fisco enquanto capacidade de coibir os interesses aristocráticos, naquelas nações que foram pioneiras na montagem do sistema colonial. Mencionando especificamente o caso da Espanha, Tilly observa que o comércio exterior propiciava aí uma fonte de recursos que "poupava" ao Estado espanhol um enfrentamento com as camadas aristocráticas e que passava a resultar, em contraste, por exemplo, com a França, em um efeito minimizado da construção do Estado na direção da transformação capitalista da sociedade. O tema reaparece fortemente no "paper" apresentado por David Landes no Congresso de Madri de 1998, bem como na maioria dos trabalhos da mesa The Cost and Benefits of European Imperialism from the Conquest of Ceuta, 1415, to the Treaty of Lusaka, 1974. ${ }^{9}$

\section{LEGADO COLONIAL E FORMAÇÃo DO ESTADO}

Essa discussão tem grande interesses para os estudiosos da construção do Estado na América Latina, tanto no campo teórico como histórico, porque afeta de diferentes maneiras a concepção historiográfica sobre o antigo sistema colonial e seu papel na constituição do capitalismo. Em particular, ela diz respeito aos efeitos do colonialismo ibérico na criação de uma determinada ordem colonial, base para o desenvolvimento subsequente dos Estados latinoamericanos. Parece evidente que qualquer reflexão sobre a especificidade do processo de construção do Estado na América Latina deve levar em conta as profundas diferenças entre a economia do Antigo Regime na Europa e a ordem colonial, bem como as inter-relações entre elas. Isso é importante não apenas porque a ordem colonial e as instituições herdadas é que servirão de base para a futura construção estatal na América Latina como também pelo fato de que essas instituições são criaturas do Estado absolutista ibérico. Por outro lado, os Estados latino americanos deverão ser formados no interior de um sistema internacional de Estados, cujas estruturas estavam sendo revolucionadas pelas revoluções liberais e estavam se constituindo enquanto Estados-nações. Os Estados latino-americanos emergem também no contexto da construção de Estados nacionais, isto é, almejando um lugar no concerto das nações que emergiam sob a égide do pensamento liberal. A tensão entre o legado colonial e o horizonte liberal veio a marcar de forma profunda o processo de construção estatal na América Latina.

8 Charles Tilly, Coercion, op. cit., cap. 3.

9 A mesa foi organizada por Patrick Karl O'Brien e Leandro Prados de la Encosura. Os principais "papers" apresentado estão publicados na Revista de Historia Económica, num. 1, año xvı, 1998, Madrid. 
Nas formações políticas emergentes na América Latina no século XIX a construção do Estado quis dizer sobretudo: 1) lidar com a herança colonial (produtora de impulsos centrífugos e centrípetos para a construção do Estado) e 2) exercer pulsão extrativa (homens, recursos, poderes) sobre ordens privadas que tinham sua base material fundada na economia exportadora de produtos primários em que pesem as distintas formas de organização produtiva. Os detentores do controle do processo produtivo, seriam personagens decisivos desse processo, que poria em teste não só a sua capacidade de produzir riqueza, mas de construir hegemonia e consenso para gerar a nação. No caso brasileiro, ganha especial relevo o fato de que o escravismo manteve-se como forma fundamental de organização produtiva, manifestando-se como uma forma especifica de privatismo com efeitos sobre a ordem jurídica, fiscal e coercitiva do novo Estado. Embora tenha produzido efeitos centrípetos, ao criar um poderoso interesse comum na fundação do Estado brasileiro, o escravismo associou-se a diversas pulsões centrífugas, estreitando a esfera fiscal, atrasando a profissionalização das forças armadas, reduzindo a capilaridade da ordem jurídica ${ }^{10} \mathrm{e}$, de diferentes modos, associando-se a processos de manutenção do controle sobre a terra que reiteravam a força do "poder privado" e reduziam sua permeabilidade à "ordem pública"."

Assim, a absorção do liberalismo enquanto ideologia fundante do Estado brasileiro, assume todo o seu caráter contraditório. ${ }^{12} \mathrm{~A}$ inserção do Brasil na divisão internacional do trabalho que se consolidava na primeira metade do século XIX, através da reiteração do escravismo e da revitalização da atividade agro-exportadora de produtos tropicais, significava a inserção na modernidade através da "reciclagem" do arcaico, realizando as potencialidades da economia colonial na fase nacional da história do Brasil. Apesar da tensão representada pelo esforço de construção do Estado nacional sobre a ordem escravista, é fundamental não perder de vista o papel construtivo do ideário liberal tanto como "ideologia" como enquanto "utopia", no Brasil do século XIX. O ideário liberal racionaliza ao mesmo tempo a autonomia (o ideal de Estado-nação) e a dependência (a inserção subordinada na divisão internacional do trabalho). Ao mesmo tempo, e sobretudo, fornece a ideologia-instrumento para a organização do Estado - rejeita o absolutismo, legitima a monarquia constitucional e o governo representativo. Esses foram importantes fatores de aglutinação e de unidade, muito embora se assentassem sobre a dicotomia do "senhor-cidadão", da esfera "pública" e da esfera do "domínio". Não devemos nos esquecer, que aqui o liberalismo foi também ferramenta de afirmação do poder local e

10 Wilma Peres Costa, A espada de Dâmocles, o exército, a guerra do Paraguai e a crise do Império, Hucitec/Unicamp, São Paulo, 1996.

11 Para um tratamento da relação Estado/questão agrária ver Ligia Maria Osorio Silva, Terras devolutas e latifundio, Unicamp, Campinas, 1996.

${ }^{12}$ Florestan Fernandes, A revolução burguesa no Brasil, Zahar, Rio de Janeiro, 1974, cap. 3. 
associou-se a aspirações federalistas, principalmente na primeira metade do século. Como nos mostra Sergio Buarque ${ }^{13}$ nas pulsões federalistas brasileiras da primeira metade do século, combinavam-se elementos "modernos" (a influência do federalismo norte-americano), com elementos "feudais" ou "góticos" (o mandonismo local e a resistência à criação da ordem pública). $\mathrm{O}$ legado institucional colonial e a permanência da escravidão parecem ter feito mais pela manutenção da unidade e pela consolidação do centro político nas primeiras décadas do que a força centrípeta do Estado e sua capacidade de mediar conflitos. O artificialismo dessa experiência, ou, como tão bem nos apontou Caio Prado, a externalidade e o estranhamento do Estado que se criava, por esse meio, marcaram a vida brasileira durante todo o século XIX.14

Uma vertente importante da historiografia tem constantemente sublinhado os traços de continuidade institucional que marcaram as primeiras décadas da vida do Brasil como país soberano. A continuidade dinástica, a manutenção da monarquia, a independência sem luta militar prolongada e a conservação da unidade territorial da América portuguesa tem sido vistas como traços de um continuum, onde são ressaltados, particularmente, os efeitos da transmigração da família real para o Brasil em 1808 e a peculiaridade que esse fato introduziu em nosso processo de independência política. ${ }^{15}$

Essa linha de raciocínio tende a sublinhar a precocidade de nossa vocação para a de centralização e minimizar os conflitos e rupturas do nosso processo de nascimento como Estado soberano e como nação. Os fundamentos para a crítica dessa forma particular de anacronismo encontravam-se estabelecidos nas contribuições de Caio Prado Jr. e Sérgio Buarque de Holanda. Mais recentemente, uma série de estudos inovadores tem retomado a temática, abrindo novas questões sobre as múltiplas possibilidades em conflito no processo de construção do Estado e da nação. ${ }^{16}$

13 Sérgio Buarque de Holanda, "A herança colonial, sua desagregação" in História geral da civilização brasileira, Difusão Européia do Livro, São Paulo, 1972, vol. 4, t. II, pp. 9-38.

14 Caio Prado Jr., Formação do Brasil contemporâneo: colônia, Brasiliense, São Paulo, 1942, ver particularmente pp. 269-377.

${ }^{15}$ O Instituto Histórico-Geográfico Brasileiro e a obra de Francisco Adolfo de Varnhagen, tiveram papel seminal na constituição dessa visão. Cf. Arno Wehling (coord.), Origens do Instituto Histórico e Geográfico Brasileiro: idéias filosóficas e sociais e estruturas de poder no Segundo Reinado, IHGB, Rio de Janeiro, 1989.

16 Roderick J. Barman, Brazil: the forging of a nation (1798-1852), Stanford University Press, Stanford, 1988; István Jancsó, "A construção dos Estados nacionais na América Latina, apontamentos para o estudo do Império como projeto" in Tamás Smerecsányi, $J$. R. A. Lapa, Historia econômica da Independência e do Império, Hucitec/Fapesp, São Paulo, 1996; e Na Bahia, contra o Império: história do ensaio de sedição de 1798, Hucitec, São Paulo, 1996; Márcia R. Berbel, A nação como artefato: deputados do Brasil nas Cortes portuguesas, 1821-1822, Hucitec/FAPESP, São Paulo, 1999, p. 193; Valentim Alexandre, Os sentidos do Império: questão nacional e questão colonial na crise do Antigo Regime português, Afrontamento, Porto, 1993; Iara L. C. Souza, Pátria coroada: o Brasil como corpo político autônomo, UNESP, São Paulo, 1999; Rogério Forastieri da Silva, Colônia e nativismo: a História 
Devedora das reflexões desenvolvidas nesses trabalhos, nossa proposta parte das tensões que constróem a crise do antigo sistema colonial procurando compreender o papel da fiscalidade dentro dela. É fundamental reconhecer que, diferentemente da "cultura fiscal" gestada na desintegração do feudalismo, em que os impostos reais, minoram e legitimam os encargos fiscais extraídos do senhoriato feudal, na "cultura fiscal" colonial o imposto é esbulho e esse sentido estará presente não apenas nas conjuras fiscais do séculos XVII e XVIII. ${ }^{17}$ Ele se tornará parte integrante da cultura política brasileira.

Uma periodização relevante para a discussão do tema deve enfocar, a nosso ver, o período que transcorre entre as Reformas Pombalinas à estruturação final do Estado imperial, ao longo da década de 1840, com especial ênfase na análise dos debates que cercaram a reforma fiscal encetada pelo ministro Alves Branco em 1844.

Essa periodização significa 1) que nos propomos a redesenhar a trajetória descrita evitando o anacronismo de pressupor ou deduzir o formato do Estado brasileiro a que se chegou no final dos anos 40 do século passado da aparente continuidade institucional que foi peculiar ao processo político de nossa independência; 2) que pensamos gênese mesma do Estado brasileiro em complexa simbiose com a crise do sistema colonial e com os impulsos contraditórios que as políticas metropolitanas iriam engendrar para a fundação de um Estado soberano e 3) que pensamos o processo de independência e o processo de construção do Estado como coisas distintas em que contradições, paradoxos e conflitos ocupam o centro de um cenário em que se enfrentaram múltiplas alternativas de desenho territorial e organização política.

As Reformas Pombalinas nos oferecem uma periodização significativa porque introduzem fundamental viragem nas relações de extração fiscal entre metrópole e colônia, amenizando, de certa forma, a virulência das revoltas fiscais coloniais e alterando o seu sentido. ${ }^{18}$ Destacam-se, no plano fiscal e financeiro, a criação do Erário Régio em 1761 e a radical alteração dos os métodos de arrecadação e de contabilidade. Entre as décadas de 1760 e 1770 , as provedorias de capitania foram sendo transformadas em juntas de fazenda, diretamente subordinadas ao erário português e presididas pelo vice-rei, na capitania sede e pelos governadores nas demais capitanias. Elas tem o seu po-

como "biografia da nação", Hucitec, São Paulo, 1997; Demétrio Magnoli, O corpo da pátria: imaginação geográfica e política externa no Brasil (1808-1912), Edunesp, São Paulo, 1997.

${ }^{17}$ Luciano Figueiredo, op. cit.; Maria de Lourdes Vianna Lyra, "Centralização, sistema fiscal e autonomia provincial no Império Brasileiro" (mimeo); "Dízimos reais na capitania de S. Paulo, contribuição à história tributária do Brasil colonial", tese mestrado, FFLCH-USP, 1971; A utopia do Poderoso Império, Sette Letras, Rio de Janeiro, 1994.

${ }^{18}$ Luciano Figueiredo, "Revoltas, fiscalidade e identidade colonial na América Portuguesa", tese doutorado, FFLCH-USP, 1996; ver também, Mauro de Albuquerque Madeira, Letrados, fidalgos $e$ contratadores de tributos no Brasil colonial, Sindifisco, Brasília, 1993; Graça Salgado (coord.), Fiscais e meirinhos: a administração no Brasil colonial, Nova Fronteira, Rio de Janeiro, 1990. 
der aumentado, passando a se responsabilizar pelo pagamento das folhas civis, militares e eclesiásticas, ao mesmo tempo em que são introduzidos novos métodos contábeis, controle semestral através de balanços de receita e despesa, tornando a arrecadação mais eficaz e racional.

Assim, a administração fazendária colonial deixava de compreender duas instâncias hierárquicas representadas pelo provedor mor e pelos provedores das capitanias. A nova modalidade, ao mesmo tempo em que ampliava os poderes das juntas de fazenda nas capitanias, buscava centralizar os poderes na metrópole, criando ligação direta entre os órgãos fazendários nas capitanias e seus congêneres metropolitanos. Ampliava-se, dessa maneira, a esfera de participação dos colonos na esfera administrativa, ao mesmo tempo em que se consagrava a capitania como uma jurisdição fiscal dotada de autonomia em relação a outras esferas da administração colonial fora dela. O que era concebido nos termos da centralização metropolitana iria apr esentar efeitos contraditórios na medida em que a vertente de acontecimentos trouxe a sede da monarquia portuguesa para o Brasil em 1808 e sobretudo quando a Revolução do Porto buscou incentivar a autonomização das capitanias/províncias, retirando-as da jurisdição do príncipe $\mathrm{D}$. Pedro. A peculiaridade do nosso processo de independência e a continuidade dinástica que o caracterizou não deve obscurecer o fato de que, concomitantemente com o processo de concentração de poder que caracterizava a formação do Estado monárquico e unitário, desenvolviam-se forças que iriam resistir ao movimento de extração do novo centro político, buscando conservar autonomias que eram ameaçadas pelo projeto de monarquia unitária e de continuidade dinástica. Dessa maneira é preciso reconhecer que, tão importantes quanto o "legado" centralizador, foram as profundas raízes de autonomismo provincial deixadas pelo passado colonial e que iriam resistir a um processo de construção estatal que tendia a se apresentar como interiorização da metrópole. ${ }^{19}$

${ }^{19}$ Maria Odila da Silva Dias, "A interiorização da metrópole (1808-1853)" in Carlos Guilherme Motta, 1822 Dimensões, Perspectiva, São Paulo, 1972, pp. 160-84. O ponto de partida para a discussão da formação do Estado brasileiro e de sua natureza é o debate clássico entre Nestor Duarte e Raymundo Faoro, cf. Raymundo Faoro, Os donos do poder: formação do patronato político brasileiro, P. A., Globo/Edusp, São Paulo, 1975, e Nestor Duarte, A ordem privada e a organização política nacional: contribuição à sociologia política brasileira, Cia. Ed. Nacional, São Paulo, 1939. Recentemente o debate sobre o Estado Imperial foi bastante enriquecido. Ver principalmente, José Murilo de Carvalho, A construção da ordem. A elite política imperial, Campus, Ed. UnB, Rio de Janeiro/Brasília, 1980; Teatro de sombras. A política imperial, Vértice/IUPERJ, São Paulo/Rio de Janeiro, 1988 e Fernando Uricoechea, $O$ minotauro imperial -a burocratização do Estado patrimonial brasileiro no século XIX, Difusão Européia do Livro, São Paulo/Rio de Janeiro, 1978. Ver também José Murilo de Carvalho, "Federalismo y Centralización en el Imperio Brasileño: historia y argumento" in Marcelo Carmagnani (coord.), Federalismos latinoamericanos: México/Brasil/Argentina, Fondo de Cultura Económica, México, 1993. Em outra tradição teórica ver também Ilmar Rohloff de Mattos, O tempo saquarema. A formação do Estado imperial, Hucitec, São Paulo, 1987, e Luiz Felipe de Alencastro, "Le commerce des vivants: traite d'esclaves et "pax lusitana" dans l'Atlantique Sud", tese de doutoramento, Univ. de Paris X, 1985-1986 (mimeo). 


\section{AS FONTES}

Tratando das fontes para a compreensão desse processo, devemos ressaltar sobretudo os trabalhos de compilação da Legislação Colonial no período proposto, como os de Marcos Carneiro de Mendonça e a excelente contribuição dos pesquisadores do Arquivo Nacional, esta última, com uma exaustiva listagem de fontes. ${ }^{20}$ Muitos documentos importantes para o estudo da fiscalidade na colônia e nos anos iniciais do Império foram publicados nos Anais da Biblioteca Nacional, e na Revista do Instituto Histórico e Geográfi$c o$, tonando indispensável uma consulta às suas coleções.

A partir de 1808, com o estabelecimento da Corte no Brasil, uma série de transformações são introduzidas na estrutura fiscal: o esforço de centralizar a arrecadação, a introdução de novos impostos e o estabelecimento de uma política de livre-comércio. Sobre o período joanino torna-se muito útil o saboroso relato de Luiz Gonçalves dos Santos (Padre Perereca) ${ }^{21}$ bem como a Memória de José da Silva Lisboa, com preciosas informações sobre o regime tributário e a situação financeira da época. ${ }^{22}$

Uma das peculiaridades da história tributária brasileira e que se associa às diversas "continuidades" que marcaram a transição para a vida autônoma foi a prorrogação da vigência dos impostos coloniais, depois da independência, à espera de que, passada a turbulência inicial, fossem criadas as condições para o tratamento da questão. Esse momento não ocorreu durante a Primeira Constituinte, nem ao longo de todo o século XIX. Assim, na história parlamentar brasileira não existe um "momento fundador" em que a questão dos impostos fosse discutida na perspectiva da fundação do Estado e da cidadania. Em outras palavras, tínhamos impostos mas não tivemos o "contribuinte", enquanto conceito ou enquanto militância. Essa "não-ruptura", essa "ausência de um momento fundador" parece ser uma especificidade importante da nossa formação, e não passou desapercebida dos "Fundadores do Império". Refletindo sobre ela, dizia Paulino José Soares de Souza, um dos principais artífices do Estado imperial brasileiro: ${ }^{23}$ "Há certas épocas, certas circunstâncias, certos

${ }^{20}$ Marcos Carneiro de Mendonça, Raízes da formação administrativa do Brasil, IHGB, Rio de Janeiro, 1972, 2 vols.; Graça Salgado (coord.), Fiscais e meirinhos: a administração no Brasil colonial, Nova Fronteira, Rio de Janeiro, 1990. Ver também os estudos específicos de Marcos Carneiro de Mendonça sobre o período pombalino: $O$ marquês de Pombal e o Brasil, Ed. Nacional, São Paulo, 1960, e O Erário Régio no Brasil, Ministério da Justiça, s. 1., 1968.

${ }^{21}$ Luis Gonçalves dos Santos, "Padre Perereca", Memórias para servir à história do Reino do Brasil, Ed. Itatiaia/Edusp, São Paulo, 1981.

22 José Maria Lisboa, Memória dos benefícios politicos do governo de el rei, o senhor D. João VI, Arquivo Nacional, Rio de Janeiro, 1940. O repertório dessa legislação encontra-se compilada por José Paulo de Figueiroa Nabuco de Araújo, Legislą̧ão brasileira ou Coleção cronológica das leis, decretos, resoluções de consulta, provisões, etc. do Império do Brasil desde o ano de 1808 até 1831, inclusive, Villeneuve, Rio de Janeiro, 1836-1844, 7 vols.

23 Citado em José Antônio Soares de Souza, A vida do visconde do Uruguai, Cia. Editora Nacional, São Paulo/Rio de Janeiro, 1944, p. 222. 
homens, certas nações, que podem dar à sua política uma direção diversa daquelas que lhes imprimiu o passado, dominar os acontecimentos e mudarlhes rapidamente a face. Não estamos nesse caso. Todo o nosso passado nos embaraça por tal modo, que só lentamente nos podemos ir livrando das peias que nos pôs."

Nossa hipótese de trabalho é a de que a ausência desse "momento fundador" não se confunde com continuidade. Pelo contrário, a crise financeira enfrentada durante todo o Primeiro Reinado expressava sobretudo a crise do sistema arrecadador do Antigo Regime, concebido para fazer da metrópole, a sócia privilegiada da produção colonial. Os impostos diretos sobre a produção nas suas várias modalidades formavam a parte principal desse sistema. Seu funcionamento dependia fundamentalmente de uma complexa rede de funcionários régios e de agentes privados (arrematadores, contratadores), que compravam à Coroa o direito de arrecadar os diversos impostos, beneficiandose com a diferença entre o preço contratado é a renda auferida da extração exercida sobre os produtores. O período que se desenvölve da efetivação da independência à 1850 caracteriza-se pela crise e colapso desse sistema arrecadador e no estabelecimento de uma estrutura centrada nas receitas alfandegáriàs. $\mathrm{O}$ estudo das tensões em torno da arrecadação e da modificação do sistema físcal ao longo desses anos, permite lançar alguma luz sobre as polêmicas énvolvidas na "crise endêmica" das finanças do setor público que marcou as duas primeiras décadas que se seguiram à independência procurando rèlacioná-las com a dinâmica da "economia real". ${ }^{24}$

O processo de trańsformação do sistema fiscal "colonial" em "nacional" foï lento, conflituoso e multifacetado. Os elementos para sua compreensão estão esparsos por uma extensa documentação. As fontes primárias principais para a compreensão desșe processo são os Relátórios do Ministério da Fazenda, onde se delineia o panorama da situação financeira da Corte e das províncias, a situação da dívida pública, as questões monetárias e sobretudo, as sugestổes no sentido do aperfeiçoamento do sistema tributário. Pobres e imprecisos quanto

24 Ver, sobre isso a polêmica que se estabeleceu a partir da revisão das posições de Celso Furtado (Formação Econômica do Brasil, 1959), sobre a economia no momento da Indepèndência. Justamente por partir da constatação da penúria das contas públicas, Celso Furtado parece ter subestimado o dinamismo econômico da região sudeste, em particular as atividades relacionadas com o mercado interno. Ver, sobre isso Alcir Legnaro, As tropas da moderação, Ed. Símbolo, São Paulo, 1979, bem como Ronaldo Marcos dos Santos, "Nem tudo que reluz vem do ouro..." in Tamás Smerecsányi (coord.), Historia econômica do período colonial, e Rui Granziera, "A reinserção' nó mercado mundial" in Tamás Smerecsányi (coord.), História econômica da independência, op. cit. Ver também Cecília Helena de Salles Oliveira, A astúcia liberal. Relações de mercado e projetos políticos no Rio de Janeiro (1820-1824), EDusf/Ícone, Bragança Paulista, 1999; J. L. R. Fragoso, Homens de grossa aventura: acumulação e hierarquia na praç̧a mercantil do Rio de Janeiro (1790-1830), Árquivo Nacional, Rio de Janeiro, 1992, e do mesmo autor ' M. Florentino, O arcaísmo como projeto: mercado atlântico, sociedade agrária e elite mercantil no Rio de Janeiro (c.1790-c.1840), Diadorim, Rio de Janeiro, 1993. 
aos dados, os Relatórios da primeira década após a independência, são preciosíssimos pela transparência com que expressam a crise financeira e discutem alternativas. Ao longo do período monárquico, os relatórios tenderão a ganhar cada vez mais precisão técnica e rigor informativo. Tenderão também, depois de 1850, a usar uma linguagem mais moderada, perdendo a contundência dos primeiros tempos. Em suas páginas, porém estão os principais debates teóricos da época. Também importante para o entendimento da política fiscal são as Atas do Conselho de Estado e sobretudo as Consultas à Sessão da Fazenda daquele Conselho, verdadeiro cadinho de formulação política da monarquia, particularmente no Segundo Reinado. ${ }^{25} \mathrm{~A}$ transformação da legislação tributária ao longo do período e a definição de seus marcos fundamentais a partir de 1831 está nas Coleções de Leis e Decretos do Império do Brasil. Embora a pesquisa documental seja indispensável, alguns esforços de compilação propiciam importante ponto de partida. ${ }^{26}$

Com a criação da competência fiscal da província, parte significativa da informação sobre impostos passa a estar contida nos relatórios de presidentes de província, cujos dados nem sempre estão consolidados no Relatório do Ministério.

Recentemente, o Centro de Documentação da Universidade de Chicago prestou inestimável serviço aos pesquisadores de história do Brasil, disponibilizando pela Internet um conjunto impressionante de documentos, que incluem todos os relatórios ministeriais brasileiros do século XIX, bem como os relatórios do presidentes de província e mensagens dos presidentes de Estado até $1930 .{ }^{27}$

No outro extremo do debate, podemos acompanhar as discussões do orçamento nos debates parlamentares da Câmara e do Senado. A exploração dos debates parlamentares em torno da questão tributária, permite mapear e reconstituir a tensão entre as propostas que emergem do Estado vis-a-vis as clivagens sociais e sobretudo regionais em torno da arrecadação. Particularmente relevantes são os debates que se concentram entre 1828-1831, onde se pode perceber a importância da questão fiscal no aguçamento da crise política que conduziria à abdicação. Importante também é a reconstituição da turbulência

25 José Honório Rodrigues (coord.), Atas do Conselho de Estado, Senado Federal, Brasília, 1978; Consultas da Seção da Fazenda do Conselho de Estado desde o ano em que começou a funcionar o mesmo Conselho de Estado até o presente. Coligidas por ordem do Governo, Tipografia Nacional, Rio de Janeiro, 1871.

26 Colęção das Leis do Império do Brasil, Imprensa Nacional, Rio de Janeiro, 1831-1889. Partimos de Viveiros de Castro, "História tributária do Brasil", Revista do Instituto Histórico e Geográfico do Brasil, t. LXXVIII, parte 1, 1915. Na mesma revista é de grande utilidade o Tomo Especial (1922), vol. vil, referente ao Congresso Internacional de História da América, todo ele dedicado ao histórico das tarifas aduaneiras no Brasil. Para um panorama geral da questão ver também Guilherme Deveza, "Política tributária no período imperial" in Sérgio Buarque (coord.), op.cit., t. II, vol. IV, pp. 60-85, e Ronaldo Marcos dos Santos, "Aspectos econômicos, políticos e tributários do Império Brasileiro", Relatório do Projeto Balanço e Perspectivas do Federalismo Fiscal no Brasil, IESP-FUNDAP, São Paulo, 1994 (mimeo).

27 Os documentos podem ser encontrados em http://www.crl.uchicago.edu 
que circunda a criação da competência fiscal das províncias, definida pela primeira vez no Ato Adicional (1834) ao mesmo tempo em que se criavam as assembléias provinciais (conselhos) e os efeitos da Lei n. 99 de 31 de outubro de 1835, que especificou os rendimentos do poder central, tornando-se a base da estrutura tributária do Império. O sentido da estruturação fiscal feita na regência foi o de extrair das províncias o direito de taxar o comércio exterior, aquele que viria a ser o item mais importante da receita pública.

O estudo dos efeitos contraditórios dessa legislação é essencial para entender os conflitos que permearam as década de 1830 e $1840,{ }^{28}$ que vem a incorporar as distintas formas de oposição ao processo extrativo que se irradiava a partir do Rio de Janeiro. Oposições de natureza variada, onde se mesclam elementos urbanos e rurais (Revolução Praieira), resistências provinciais contra o centro (Revolução Farroupilha), rebeliões oligarquicas contra a extração do poder pelo centro político (revoluções liberais de S. Paulo e Minas), guerras sociais e raciais (Revolução dos Malês, Cabanagem).

Em 1837 e, especialmente em 1843, associada à primeira discussão do Projeto de Lei de Terras destaca-se o debate em torno da introdução do imposto territorial, de extrema importância para compreender as resistências às formas diretas de taxação da propriedade e da riqueza. No outro extremo, o período que recortamos, é balizado pela reformas fiscais da década de 1840, em particular da administração fazendária do ministro Alves Branco, que vieram a concretizar, no plano fiscal, o estabelecimento dos impostos sobre a importação como fonte principal das receitas do Estado. Essas reformas, a nosso ver, encerram o ciclo formativo do Estado imperial, completando o processo de nacionalização do sistema fiscal, em estreita simbiose com os interesses da agricultura de exportação. A Reforma Alves Branco, foi particularmente decisiva seus efeitos políticos - a capacidade de fazer conciliar, em um momento crítico para a consolidação do centro político, conflitos regionais e sociais em torno do financiamento da máquina pública.

Acompanhando a discussão em torno dos impostos no plano do debate parlamentar, pretendemos estudar o jogo de pressões envolvido no esforço organizador do Primeiro Reinado e da Regência, onde se exacerbaram as pulsões centrífugas e a crise financeira do Estado em formação. Os debates em torno da reforma tarifária da gestão Alves Branco permitem visualizar o jogo de interesses envolvido na consolidação do Estado, bem como aquilatar os limites da centralização imperial. ${ }^{29}$

28 Para um estudo da reação provincial, referido principalmente à Pernambuco, ver Maria de Lourdes Vianna Lyra, "Centralisation, systeme fiscal et autonomie provinciale dans l'Empire Bresilien, La Province de Pernambuco 1808-1835", tese de doutoramento, Nanterre, Paris, 1985 (mimeo).

29 Ver também Brazil, Comissão encarregada da Revisão da Tarifa em Vigor, Relatório que acompanhou o projeto de tarifa apresentado pela mesma Comissão ao Governo Imperial, Typografia Dous de Dezembro de Paula Brito, Rio de Janeiro, 1853. 
Fontes também muito importantes para o estudo da fiscalidade são os relatos dos viajantes europeus do século XIX, particularmente daqueles envolvidos composições comerciais e/ou interessados na promoção da imigração. Sobre o Rio de Janeiro o trabalho mais conhecido é o de Lucock. ${ }^{30}$ Sobre as várias regiões do Brasil no momento da independência, não se pode deixar de ler, pela sensibilidade política e pela riqueza de detalhes as narrativas de SaintHilaire. ${ }^{31}$ Dentre os viajantes, alguns foram "especialistas" em assuntos econômicos e financeiros, que vieram ao Brasil para promover interesses comerciais de países europeus, dentre eles a imigração. Está nesse caso o trabalho de J. J. Sturz, que retrata a situação do Brasil em 1837, com agudas observações sobre os temas monetários. ${ }^{32}$

O mais importante tratamento qualitativo da questão fiscal do Império Brasileiro foi obra de um erudito viajante belga, o conde Auguste van der Straten-Ponthoz, que produziu um soberbo estudo, onde a análise do orçamento é apenas um ponto de partida para uma compreensiva interpretação do Brasil e dos obstáculos impostos à imigração européia pela ausência de uma política tributária progressista. ${ }^{33}$ Foi também um estudioso alemão, interessado na promoção da imigração alemão para o Brasil, o autor da melhor história do Brasil escrita no século XIX, onde também há um excelente tratamento da problemática fiscal. ${ }^{34}$

Um dos debates mais importantes da vida política do Império foi o que se desenvolveu, a partir da década de 1860 , entre os defensores da centralização política e os que propugnavam maior autonomia provincial. A discussão afeta, em múltiplos aspectos a compreensão das finanças públicas e da organização do poder do Estado, bem como a relação entre o poder central e as forças políticas locais e regionais. As posições polares estão representadas por Paulino Soares de Souza e Aureliano Cândio Tavares Bastos . ${ }^{35}$

No início do período republicano produziram-se trabalhos importantes de compilação e análise da política fiscal, monetária e financeira do período mo-

30 John Lucock, Notas sobre o Rio de Janeiro, S.P. Ed. Itatiaia/Edusp, 1976.

${ }^{31}$ Auguste de Saint-Hilaire, Viagem pelas províncias do Rio de Janeiro e Minas Gerais, Ed. Itatiaia/Edusp, São Paulo, 1975; Viagem pelos distritos dos diamantes e litoral do Brasil, Ed. Itatiaia /Edusp, São Paulo, 1974; Viagem às nascentes do rio São Francisco, Ed. Itatiaia/Edusp, São Paulo, 1975; Segunda viagem do Rio de Janeiro às Minas Gerais e São Paulo, Ed. Itatiaia/Edusp, São Paulo, 1974.

32 J. J. Sturz, A review, financial, statistical \& commercial of the Empire of Brazil and its ressources, Londres, 1837.

33 Auguste van der Straten-Ponthoz (Comte), Le budget du Brésil, ou recherches sur les ressources de cet Empire, dans leur rapports avec les interêts europeens du commerce et de l' émigration, Libairie L'Amyot Editeur, Paris, 1854.

34 H. Handelmann, História do Brasil, Ed. Itatiaia/Edusp, 4a. ed., São Paulo, 1982.

35 A.C. Tavares Bastos, A província, Cia. Ed. Nacional, 2a. ed. São Paulo/Rio de Janeiro, 1937; Paulino José Soares de Souza, Ensaio sobre o direito administrativo, Tipografia Nacional, Rio de 
nárquico. Marcados pela crise financeira que acompanhou os anos iniciais da República, alguns destes trabalhos refletiam a polêmica entre os adversários e defensores do novo regime e buscavam, no esquadrinhamento dos dados referentes ao período monárquico, argumentos para alimentar as diferentes posições. O trabalho mais utilizado pelos estudiosos, por resumir todos os orçamentos do período imperial, é o de Liberato Castro Carreira. ${ }^{36}$ Crítica veemente da política republicana e reconstituição elogiosa da política financeira da monarquia encontra-se na coletânea publicada pelos exilados monarquistas, A década republicana.$^{37}$ Do outro lado da polêmica, localizam-se os trabalhos dos intelectuais e políticos republicanos como Felisbelo Freire e Amaro Cavalcanti, este último, importante estudioso da historia monetária e financeira do período monárquico. ${ }^{38}$

Os dados oficiais estão compilados no volume de Estatísticas históricas do Instituto Brasileiro de Geografia Estatística. ${ }^{39}$ Embora os dados estejam aí bastante agregados, permitem produzir séries estatisticamente relevantes bem como explorar os aspectos qualitativos sugeridos pelos dados, como o impacto da arrecadação sobre as diferentes regiões e o estudo do gasto público e sua destinação. Dentre os esforços acadêmicos é importante mencionar, pela visão panorâmica e pela concepção geo-política da questão, o trabalho pioneiro de Normano. ${ }^{40}$

A história da criação e da transformação dos tributos tem, lamentavelmente, suscitado menos interesse nos acadêmicos atuais, muito embora a questão fiscal continue a ser um dos mais candentes temas da política econômica e do debate político. ${ }^{41}$ Poucos tem sido os esforços no sentido de dar um tratamento mais elaborado aos dados do século XIX. ${ }^{42}$ Os historiadores econômicos atuais, ao contrário de seus antecessores do século XIX, tem desenvolvido a tendência

Janeiro, 1862. Sobre o debate ver Gabriela Nunes Ferreira, Centralização e descentralização no Império -o debate entre Tavares Bastos e o visconde do Uruguai, Ed. 34, São Paulo, 1999.

${ }^{36}$ Liberato Castro Carreira, História financeira e orçamentaria do Império do Brasil, Sen. Federal/Fundação Casa Rui Barbosa/MEC, Brasília/Rio de Janeiro, 1980.

37 Affonso Celso de Assis Figueiredo (visconde de Ouro Preto) et al., A década republicana, UNB, Brasília, 1986.

"38 Felisbelo Freire, História constitucional da República dos Estados Unidos do Brasil, UNB, Brasília, 1985; Amaro Cavalcanti, Resenha Econômico-Financeira do Ex-Império do Brasil, Imprensa Nacional, Rio de Janeiro, 1890, e O meio circulante nacional (1808-1835), uNB, Brasília, 1983.

39 IBGE, Estatísticas históricas do Brasil, Séries econômicas, demográficas e sociais, 15501988, IBGE, 2a. ed., Riọ de Janeiro, 1990.

40 J. F. Normano, Brazil, a study of economic types, University of Carolina Press, Chapel Hill, 1935, pp. 114-163.

41 O tema permanece, entretanto, entre aqueles que tem formação sociológica. Ver, por exemplo, Maria Valéria Pena, Formação do Estado e de sua fiscalidade. A gênese do imposto de renda no Brasil, IEI-UFRJ, Rio de Janeiro, 1991 (Série Documentos, num. 3).

42 Algumas contribuições no tratamento das séries estatísticas, sempre subsumidas à temática financeira mais geral, estão em Raymond Goldsmith, Brasil (1850-1984)-Desenvolvimento financeiro sob um século de inflação, Harper \& Row, São Paulo, 1986. 
de dar um tratamento técnico e despolitizado aos assuntos fiscais. As finanças públicas tem sido estudadas mais sob a ótica da política monetária e financeira do que em sua relação com as articulações de interesses que permeiam a vida social e a ação política. Refletem, nesse sentido, a despolitização generalizada das questões públicas e, mesmo sem o desejar, contribuem para ela. Nosso interesse, ao apresentar essa discussão sobre as fontes para o estudo das finanças públicas e, nelas enfatizar a história dos tributos é buscar compreender uma peculiaridade perversa de nossa formação histórica e de nossa cultura política: a relativa fraqueza, para não falar na ausência, em nossa vida pública do nexo dinâmico entre taxação e representação, entre a formação do contribuinte e do cidadão. Da mesma maneira, ou como uma outra faceta da mesma questão, tentar compreender porque os conflitos em torno da política tributária tem sempre resvalado para a esfera da disputa regional, dificultando a visão dos efeitos do reiterado privatismo no atraso da construção do espaço público entre nós. 


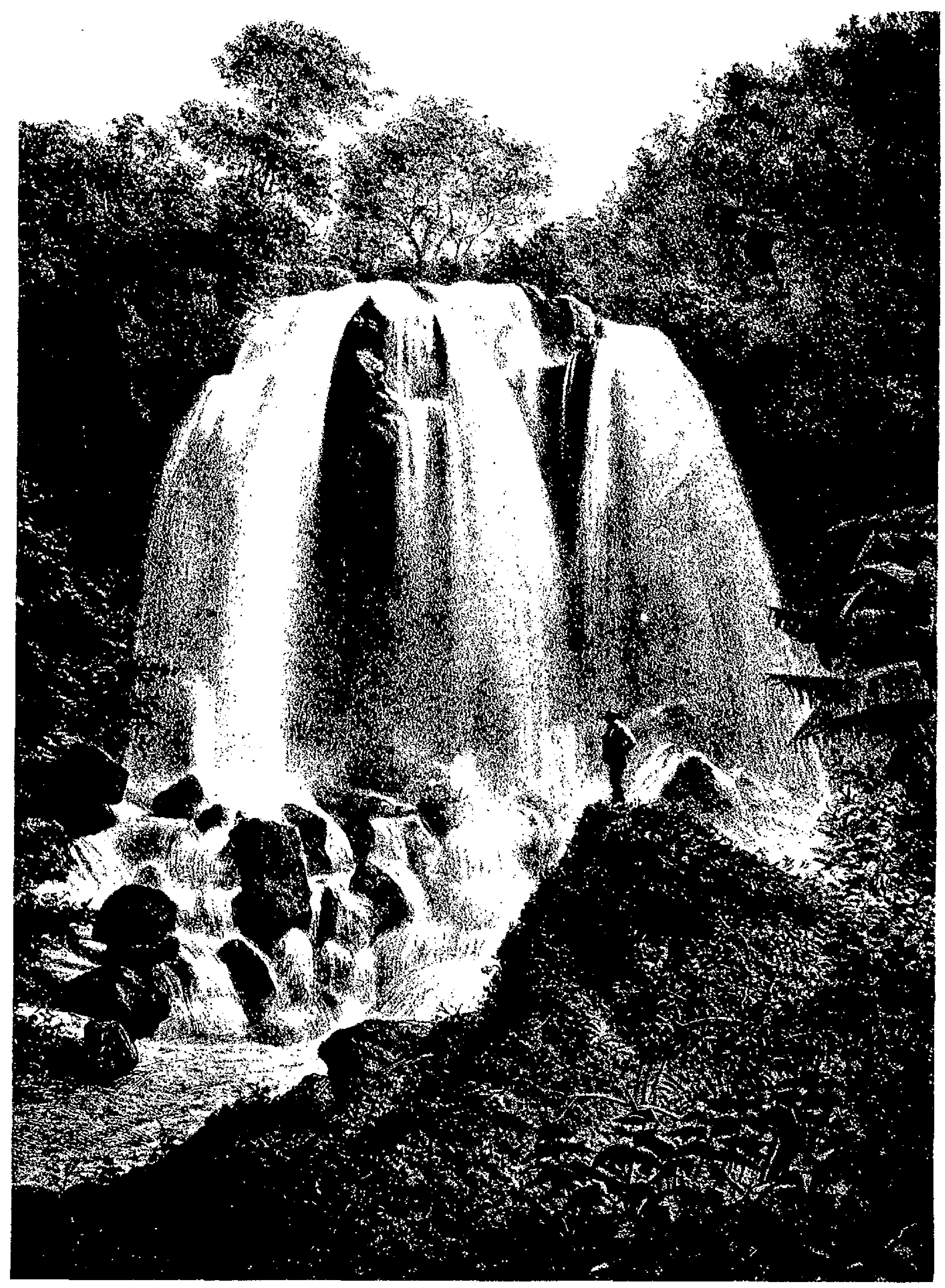

